\title{
Material Model of AW 5754 H11 Al Alloy for Numerical Simulation of Deep Drawing Process
}

\author{
Marek Šiser ${ }^{1, *}$, Ján Slota ${ }^{1}$
}

${ }^{1}$ Technical University of Košice, Faculty of Mechanical Engineering, Department of Computer Aided Technologies, Letná 9, 04001 Košice, Slovak Republic

\begin{abstract}
The aim of this work is to create material model for aluminum material AW $5754 \mathrm{H} 11$ for numerical simulation, which is widely used in automotive industry. For purpose of verification material model the deep drawing cup test was carried up, and measured parameters were punch force, thickness distribution and ear profile. Results from numerical simulation were validated by real experiment with regard to predict accuracy in changes of thickness and ear profile.
\end{abstract}

Keywords: deep drawing, Al alloys, sheet metal, numerical simulation.

\section{Introduction}

Using of alternative materials, based on aluminum and composites, for all autobody parts became the trend in modern automobile industry [1]. They have resulted in a steadily increasing demands for weight reduction of passenger cars. Weight reduction of automobiles have direct impact on reduction of fuel consumption, reduce emissions and driveability of car, such as acceleration, breaking performance, stability of a car and driving comfort [2]. Due to constantly increasing demands of passengers safety, it is necessary to increase the number of safety features in car. Therefore, it is expected that the weight cars will continue to increase. Aluminum alloys due to their good properties such as low weight compared to steel, high strength, low density, good corrosion resistance and easy recycling created an ideal replacement of steel in cars bodies $[3,4]$.

Formability is a complex characteristic feature, involving plastic characteristics of formed material, such as mechanical properties, normal anisotropy coefficient, strain-hardening exponent, as well as specific conditions, where we include, e.t. friction or stress space $[5,6]$. With the forming of Al alloys are associated many complications. Due to the lower strength compared to steel it is required for achieve the same strength to use thicker material. Many of the problems are also in the forming process. One is the "sticking" of material on the forming tool. Build up edge on the tool arise that need to be eliminated abrading of tools. This effect can be significantly affected using of suitable lubrication, or coating, thus reducing the friction. Another disturbing problem is susceptibility to springback. It is related to the fact that aluminum have two to three times lower modulus of elasticity than steel. There are four most common ways to reduce springback, and it is increase of holding force, the increase of material thickness, more intensive stretching and cold-forming. One of the most significant problems is also thinning. Even with thinning over than $20 \%$ is a high probability of occurrence of crack in the material $[7,8]$. 
As a result of such a large amount of problems associated with stamping of aluminum alloys, it is necessary to predict their behavior during stamping. For this purpose the finite element method (FEM) and numerical simulation can be used. The key is not only to set correct process parameters, but also create a material model that can accurately predict behavior of certain material during the forming process [9].

Presented article deals with creation of material model for aluminum material AW 5754 H11. For this purpose the FEM were used, to predict stamping of simple axially-symmetrical stamped part. Simulation model was compared with the results real experiment. Measured parameters: punch force, thickness distribution, stress and strain distribution and ear profile of the cup.

\subsection{Material models used in numerical simulation}

It is possible to predict influence of material model, friction conditions, tool geometry and stamped part on forming process by the numerical simulation. Since the enlargement FEM simulation in the field of stamping, many methods for evaluating formability of sheet metal has been developed. The most realistic were presented by Keeler and Goodwin in 1960, as FLD concept $[8,9]$.

There are a large number of works dealing with the influence of the yield criteria (e.g. Hill, Hosford, Barlat and Lian, Vegter, Karafillis - Boyce, etc.) and hardening law (e.g. Krupkowski, Hollomon, Bergrström - van Liempt etc.), sensitivity of the strain rate due to temperature or to predict the forming process. It is necessary to define input data in numerical simulation [9-13]. Significant is material model, the constitutive equation of numerical simulation. It is possible to include the yield criteria and strain-hardening law to these characteristic equations $[5,11,13]$.

\subsection{Strain-hardening}

During plastic deformation the initial material is deformed. In one point the strain slows down and occurs phenomenon called strain-hardening, and strength of material will rise in this point. After reaching this point strain continues in materials normally. Yield strength is the point when material changes the status of elastic into the plastic (Fig. 1) [14].

Hollomon and Krupkowski hardening curves belongs to input parameters of numerical simulation. Hollomon hardening curve (also called

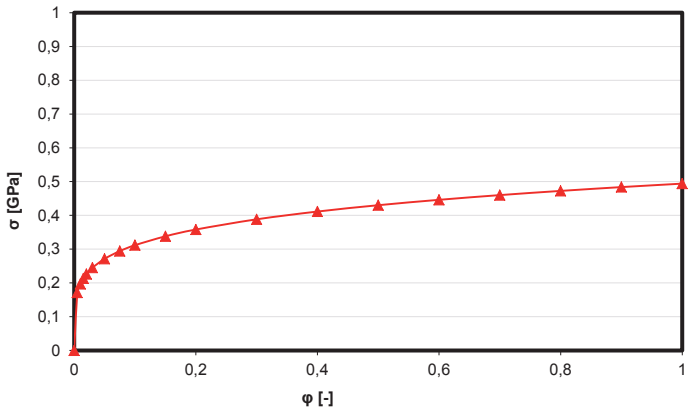

Fig. 1: Krupkowski strain-hardening law.

Ludwik hardening law) describes plastic behavior of the material between an ultimate tensile strength and ultimate tensile strength. For this hardening law two constants are needed, strainhardening exponent $n$, which characterized plastic behavior of material during cold forming, and material constant K. Hollomon hardening law is characterized by equation [15]:

$\sigma=K \cdot \varepsilon^{n}$

where: $\varepsilon$ - logarithmic strain, $n$ - strain-hardening exponent, $K$ - material constant.

Also Krupkowski hardening law (called also Swift hardening law) is widely used in FEM software. In the ductile materials we can distinguish two regions of deformation. The first one is characterized by the fact, that influence of hardening is greater than the effect of thickness reduction in cross-section on traction. This is characterized by the fact that in order to achieve an additional deformation of sample is necessary additional increases of traction. In the second area hardening is impossible to compensate by the redacting of tractive force due to reduce cross-sectional thickness of sample. This again is characterized by reducing tractive force, but stress in the sample is constantly increasing. For this type of hardening applies relation $[5,15]$ :

$\sigma=K \cdot\left(\varepsilon_{p}+\varepsilon_{o}\right)^{n}$

where: $\varepsilon_{p}$ - plastic strain, $\varepsilon_{o}$ - offset strain, $n$ - strainhardening exponent, $K$-material constant.

\subsection{Yield function}

Yield function describe plastic behavior of the material, the multiaxis stress. In simulation software can be used several yield functions.

According to Hill 48 and Hill 90 yield function, in 
the case of uniaxial stress occurs local reduction along the direction that is vulnerable in view of the direction of loading. Hill assumed that the direction of reduction is compliant with the direction of zero extension and therefore the deformation of narrowed areas only appears as reduction in thickness [16].

Yield function Hill 48 is the most frequently used material model for conventional steel sheet. Function is designed for being used in combination with isotropic hardening law. This condition is based on the assumption zero value of main stress in thickness direction, so in plane stress $\left(\sigma_{1}-\right.$ major strain, $\sigma_{2}-$ minor strain, $\left.\sigma_{3}=0\right)$. If we assume that anisotropy axis are identical with the main guidelines strain tensor $\left(\sigma_{\mathrm{x}}=\sigma_{1}, \sigma_{\mathrm{y}}=2, \tau_{\mathrm{xy}}=0\right)$, it is possible that condition to express in relation to [17]:

$$
\begin{aligned}
\sigma_{K}^{2} & =\sigma_{1}^{2}-\left(\frac{2 \cdot r_{0}}{1+r_{0}}\right) \cdot \sigma_{1} \cdot \sigma_{2}+ \\
& +\frac{r_{0}}{r_{90}} \cdot\left(\frac{1+r_{90}}{1+r_{0}}\right) \cdot \sigma_{2}^{2}
\end{aligned}
$$

where: $\sigma_{\mathrm{K}}-$ yield stress, $\sigma_{1}-$ major strain, $\sigma_{2}-$ minor strain, $\mathrm{r}_{0}, \mathrm{r}_{45}, \mathrm{r}_{90}$ - Lankford coefficients.

Hill 48 yield function is expressed from the values of normal plane anisotropy, which are derived from tensile test, where the sample is exposed in three directions $-0^{\circ}, 45^{\circ}$ and $90^{\circ}$ with respect to direction rolling. Hill 48 yield function is suitable for use in combination with isotropic hardening law. Hill 90 yield function is used for orthotropic hardening law and values of anisotropy under 1.0. This yield function is more complicated, because of its use in addition outputs from tensile test and output of biaxial test [18]. Material model was in numerical simulation defined by Hill 90 yield criteria, which is calculated according to the [18]:

$$
\begin{aligned}
& \left(\frac{\sigma_{1}}{\sigma_{0}}\right)^{2}+\left(\frac{\sigma_{2}}{\sigma_{90}}\right)^{2}+ \\
& +\left[(p+q-c)-\frac{p \sigma_{1}+p \sigma_{2}}{\sigma_{b}}\right] \cdot\left(\frac{\sigma_{1} \sigma_{2}}{\sigma_{0} \sigma_{90}}\right)=1
\end{aligned}
$$

where: $\sigma_{0}$ - uniaxial tensile stress in rolling direction, $\sigma_{90}$ - uniaxial tensile stress in direction normal to rolling direction, $\sigma_{b}$ - stress under balanced biaxial stress, c, p, q-parameters defined: $c=\frac{\sigma_{0}}{\sigma_{90}}+\frac{\sigma_{90}}{\sigma_{0}}-\frac{\sigma_{0} \sigma_{90}}{\sigma_{b}^{2}}$

$$
\begin{aligned}
\left(\frac{1}{\sigma_{0}}+\frac{1}{\sigma_{90}}-\frac{1}{\sigma_{b}}\right) p & =\frac{2 R_{0}\left(\sigma_{b}-\sigma_{90}\right)}{\left(1+R_{0}\right) \sigma_{0}^{2}}- \\
& -\frac{2 R_{90} \sigma_{b}}{\left(1+R_{90}\right) \sigma_{90}^{2}}+\frac{c}{\sigma_{0}}
\end{aligned}
$$

$$
\begin{aligned}
\left(\frac{1}{\sigma_{0}}+\frac{1}{\sigma_{90}}-\frac{1}{\sigma_{b}}\right) q & =\frac{2 R_{90}\left(\sigma_{b}-\sigma_{0}\right)}{\left(1+R_{90}\right) \sigma_{90}^{2}}- \\
& -\frac{2 R_{0} \sigma_{b}}{\left(1+R_{0}\right) \sigma_{0}^{2}}+\frac{c}{\sigma_{90}}
\end{aligned}
$$

where: $R_{0}$ - the $R$-value for uniaxial tension in the rolling direction, $R_{90}$ - the $R$-value for uniaxial tension in the in-plane direction perpendicular to the rolling direction.

According to [18] is for aluminum and high strength sheets more appropriate Hill 90 than Hill 48 yield function. More difficult conditions as the BBC2005, Corus-Vegter or Corus-Vegter Lite they requires much more information.

Vegter yield function provides the possibility to much more accurately described behavior of the material. Vegter was able to establish a first quadrant of yield function on the basis of the points of the basic experimental measurements. To combine this points Bézier curves are used. Each point must have 3 parameters (two main stresses $\sigma_{1}, \sigma_{2}$ and strain vector $\left.\rho=\mathrm{d} \varepsilon_{2} / \mathrm{d} \varepsilon_{1}\right)$. In order to describe planar anisotropy it is necessary for this model to have 17 parameters. The Bézier interpolation is described in equation 5 for $\bar{\sigma}=\sigma_{f}$ and an angle $\varphi$.

Mathematical expression of this yield function is $[15,19,20]$ :

$$
\begin{aligned}
\left(\begin{array}{l}
\sigma_{1} \\
\sigma_{2}
\end{array}\right) & =(1-\lambda)^{2}\left(\begin{array}{l}
\sigma_{1} \\
\sigma^{2}
\end{array}\right)_{i}^{r}+2 \lambda(1-\lambda)\left(\begin{array}{l}
\sigma_{1} \\
\sigma_{2}
\end{array}\right)_{i}^{h}+ \\
& +\lambda^{2}\left(\begin{array}{l}
\sigma_{1} \\
\sigma_{2}
\end{array}\right)_{i+1}^{r}
\end{aligned}
$$

where: $\varphi$ - angle between the principal axes of plane stress and the principal axes of anisotropy, $\lambda$ - parameter for Bézier interpolation.

\section{Experimental Procedure}

In this work the material AW $5754 \mathrm{H} 11$, which is age hardened, is analyzed. This material is used in 
Table 1: Chemical composition of AW 5754 H11.

\begin{tabular}{|c|c|c|c|c|c|c|c|c|c|c|}
\hline Chemica composition & $\mathrm{Mg}$ & $\mathrm{Mn}+\mathrm{Cr}$ & Mn & Si & Fe & $\mathrm{Cr}$ & Zn & Ti & $\mathrm{Cu}$ & Other \\
\hline$[\%]$ & 3.60 & 0.60 & 0.50 & 0.40 & 0.40 & 0.30 & 0.20 & 0.15 & 0.10 & 0.15 \\
\hline
\end{tabular}

Table 2: Mechanical properties of AW $5754 \mathrm{H} 11$.

\begin{tabular}{|c|c|c|c|c|c|c|c|c|c|}
\hline Dir. & $\mathrm{Rp0,2}$ [MPa] & $\mathrm{Rm}$ [MPa] & $\mathrm{A}_{80}[\%]$ & $\mathbf{r}[-]$ & $\operatorname{Im}[-]$ & $\Delta r[-]$ & $n[-]$ & $\mathrm{nm}_{\mathrm{m}}[-]$ & $\Delta n[-]$ \\
\hline $0^{\circ}$ & 146 & 231 & 14.7 & 0.655 & \multirow{3}{*}{0.797} & \multirow{3}{*}{-0.214} & 0.282 & \multirow{3}{*}{0.283} & \multirow{3}{*}{-0.000} \\
\hline $45^{\circ}$ & 136 & 220 & 19.6 & 0.904 & & & 0.283 & & \\
\hline $90^{\circ}$ & 137 & 221 & 18.8 & 0.723 & & & 0.283 & & \\
\hline
\end{tabular}

the inner body parts, as it creates Lüders bands. Material thickness is $0.8 \mathrm{~mm}$, with an average strength $140 \mathrm{MPa}$ and good corrosion resistance. Its chemical composition is listed in Table 1.

Mechanical properties of the material have been measured by tensile test on the device TiraTEST 2300. Basic mechanical properties are set out in Table 2.

Deep drawing cup test has been carried out on the universal testing machine Erichsen 14560. Blank used in an experiment was created by cutting tool placed directly in the test machine with diameter $\varnothing 90 \mathrm{~mm}$. Diameter of the punch was $\varnothing 50 \mathrm{~mm}$ and height of cup reached during the test was on average $30.5 \mathrm{~mm}$. The resulting extract can be seen in Figure 2 (a). Holding force has been set to the value 8 codes and to reduce friction was used PTFE foil.

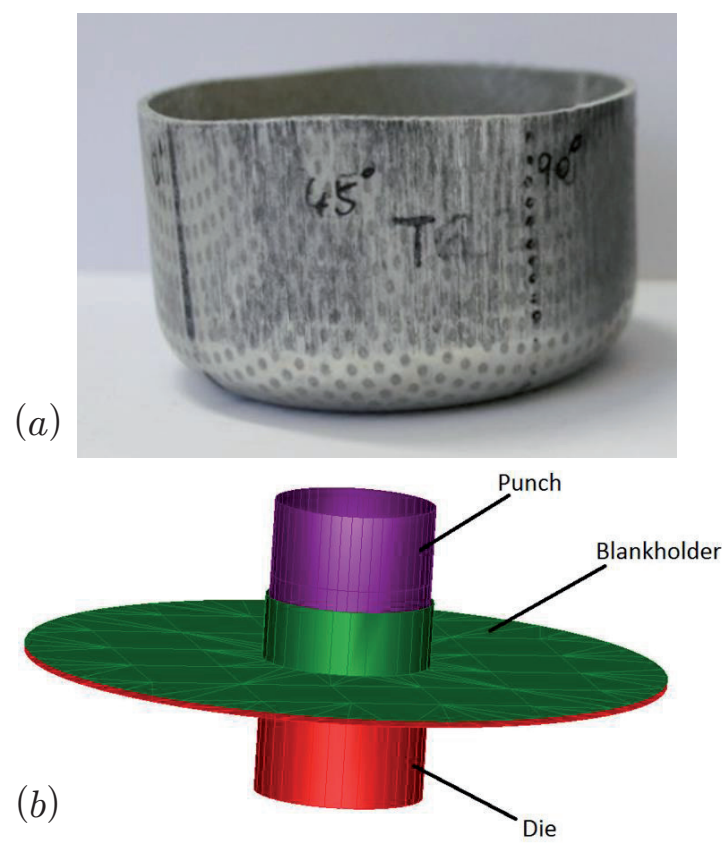

Fig. 2: (a) Drawn part. (b) 3D model of stamping tool.
During the deep drawing process large amount of material transfer. For this transfer big tangential stress is needed. This tangential stress is usually higher than strength of material in buckling, what results in the wrinkling. Blankholder is usually used to prevent this wrinkling (Figure 2 (b)). As has been mentioned this work is dealing with accuracy of material model for numerical simulation to predicting deep drawing process of Al sheet, with a focusing to the yield function and work hardening as a parameters, which largely affects results [19]. As for the simulation of the test, the FE explicit code was used to solve the problem. Parameters of numerical simulation process are given in the Table 3:

Table 3: Mechanical properties of AW 5754 H11.

\begin{tabular}{|c|c|c|c|}
\hline Parameter & Value & Parameter & Value \\
\hline Mesh type & Quadrilateral & $\begin{array}{l}\text { Element } \\
\text { type }\end{array}$ & Shell \\
\hline Mesh size & $5 \mathrm{~mm}$ & $\begin{array}{c}\text { Friction } \\
\text { coefficient }\end{array}$ & 0.05 \\
\hline $\begin{array}{l}\text { Level of } \\
\text { refinement }\end{array}$ & 2 & $\begin{array}{c}\text { Yield } \\
\text { function }\end{array}$ & $\begin{array}{c}\text { Hill48/ } \\
\text { Hill90/ } \\
\text { Vegter Lite }\end{array}$ \\
\hline $\begin{array}{l}\text { Mesh } \\
\text { size after } \\
\text { refinement }\end{array}$ & $1.25 \mathrm{~mm}$ & $\begin{array}{l}\text { Hardening } \\
\text { curve }\end{array}$ & $\begin{array}{l}\text { Hollomon/ } \\
\text { Krupkowski }\end{array}$ \\
\hline $\begin{array}{l}\text { Number of } \\
\text { integration } \\
\text { points }\end{array}$ & 5 & Tool mesh & $0.5 \mathrm{~mm}$ \\
\hline
\end{tabular}

On deep drawn parts can be observed deviation of cup height on theirs circumference. Difference between the minimum and maximum height is called ear profile and it can be expressed by the earing tendency $(\Delta \mathrm{H})$ : 


$$
\Delta H=\frac{H_{\max }-H_{\min }}{H_{\min }} \cdot 100[\%]
$$

where: $\mathrm{H}_{\min }$ - minimum cup height, $\mathrm{H}_{\max }$ maximum cup height.

\section{Results and Discussion}

In order to achieve best formability of the material, it is necessary for material to have low values of yield strength, high ultimate tensile strength, elongation and ratio Rp0.2/Rm as low as possible. Differences in between the maximum and minimum in all directions $\left(0^{\circ}, 45^{\circ}\right.$ and $\left.90^{\circ}\right)$ were up to $10 \mathrm{MPa}$. Coefficient of normal anisotropy $r$ was less than 1, and that means that strain occurs mainly as a deformation in thickness of the sheet.

On the basis of measurements may be created graphic comparison of ear profile (Figure 3) for material AW $5754 \mathrm{H} 11$. As it was mentioned earlier the drawn part was an axial-symmetric cup with diameter $\varnothing 50 \mathrm{~mm}$, with friction coefficient set on value $\mu=0.05$, which reply to PTFE foil. However friction coefficient will change during the process because the foil would tear after the radii of cup is formed (in the wall of the cup). This way the friction coefficient will increase and this can greatly influence the forming process [21]. To simplify the whole comparison of different yield functions and hardening laws we didn't use more friction coefficients to find the most accurate results.

\section{Ear profile}

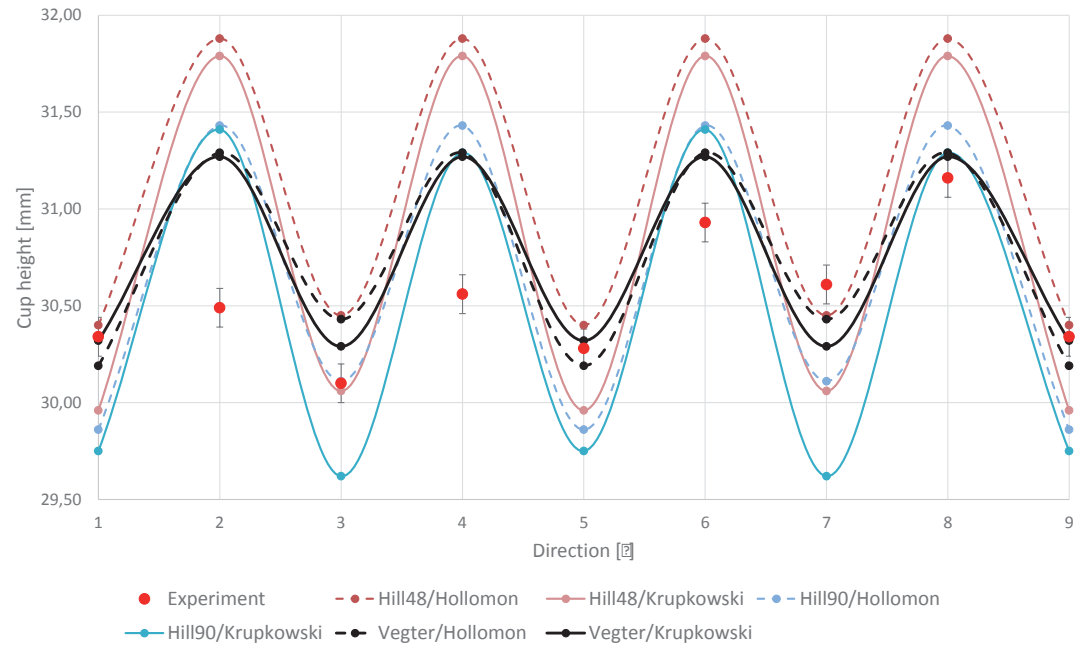

Fig. 3: Ear profile of the cups.

The measurement was carried out on the circumference of drawn part with pitch of measured points after $45^{\circ}$. Creation of the peaks is an undesirable effect during the deep drawing. Therefore materials with the lower ear profile are more suitable for deep drawing. Four peaks can be observed at angels $45^{\circ}, 135^{\circ}, 225^{\circ}$ and $315^{\circ}$ related to rolling direction. Minimum height was measured in the direction $0^{\circ}$ and others in respect to the rolling direction.

Table 4 show ear profiles of each combination of yield functions and hardening laws. It is clear, that best results are with combination of Vegter yield function and Hollomon hardening law with difference from experiment was about $0.112 \%$.
During the experiment max punch force of $22.5 \mathrm{kN}$ was measured on punch displacement value of 14-16 mm (Figure 4). At this point radii on the bottom of cup should be fully drawn. Force decreased subsequently up to $28 \mathrm{~mm}$. Then force subsequently increased, because material lost contact between die and blankholder. Force raised further as a result of the so-called ironing effect at punch displacement about $28 \mathrm{~mm}$, as a result of increased blank thickness, which occurs during the first forming phase, when material is compressed in the circumference at flange. In Figure 4 is comparisons of different combinations hardening laws and yield functions. Most of results have similar course as real experiment. At the beginning 
Table 4: Add a descriptive label of the table here.

\begin{tabular}{|c|c|c|c|c|c|c|c|}
\hline Mat. models & $\begin{array}{l}\text { Hill48/ } \\
\text { Hollomon }\end{array}$ & $\begin{array}{l}\text { Hill48/ } \\
\text { Krupkowski }\end{array}$ & $\begin{array}{l}\text { Hill9o/ } \\
\text { Hollomon }\end{array}$ & $\begin{array}{l}\text { Hill90/ } \\
\text { Krupkowski }\end{array}$ & $\begin{array}{l}\text { Vegter/ } \\
\text { Hollomon }\end{array}$ & $\begin{array}{l}\text { Vegter/ } \\
\text { Krupkowski }\end{array}$ & Experiment \\
\hline Ear profile [\%] & 4.87 & 6.11 & 5.26 & 6.04 & 3.64 & 3.24 & 3.52 \\
\hline
\end{tabular}

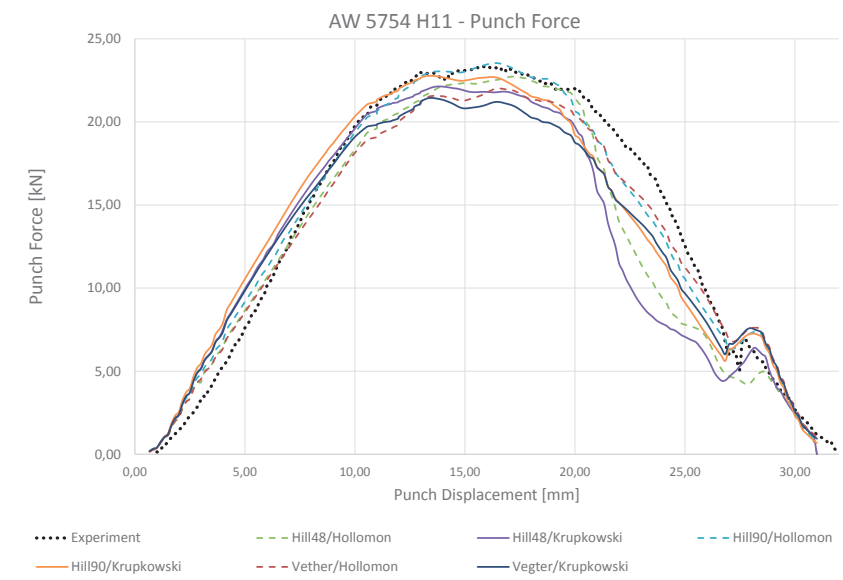

Fig. 4: Punch force of compared material models.

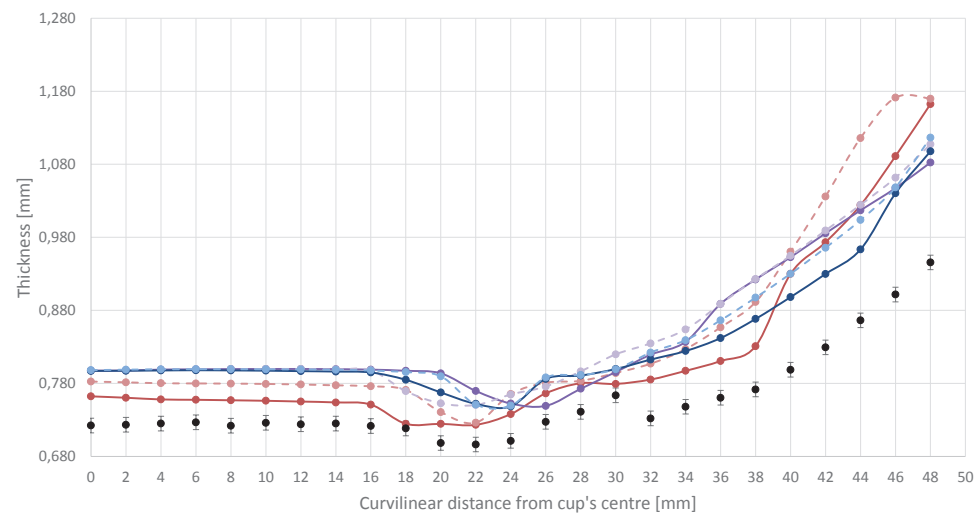

(a)

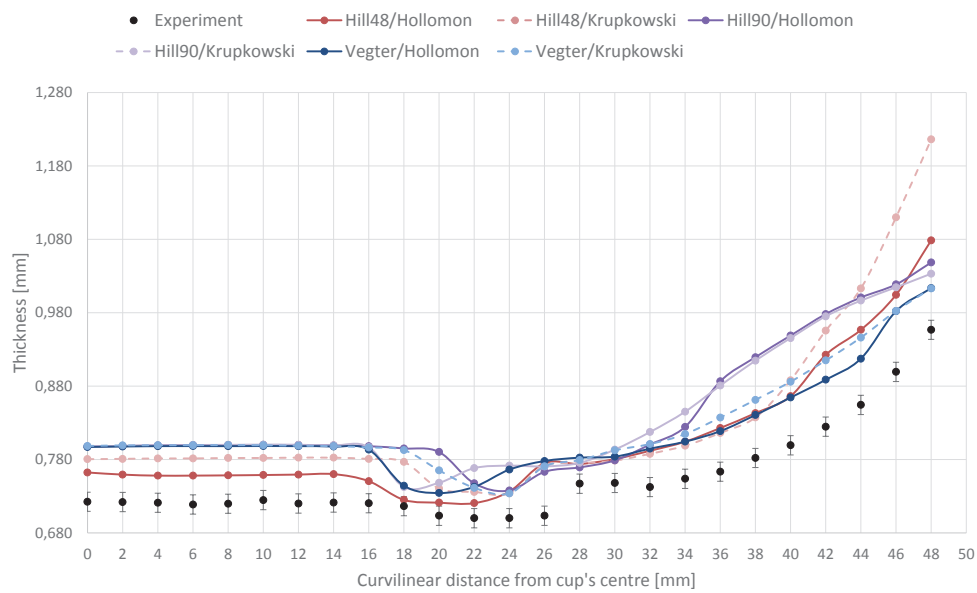

(b)

- Eperiment $\rightarrow$ Hill48/Hollomon $-\bullet$-Hill48/Krupkowski $\rightarrow$ Hill90/Hollomon

$\rightarrow$ Hillgo/Krupkowski $\rightarrow$-Vegter/Hollomon $-\bullet$-Vegter/Krupkowski 


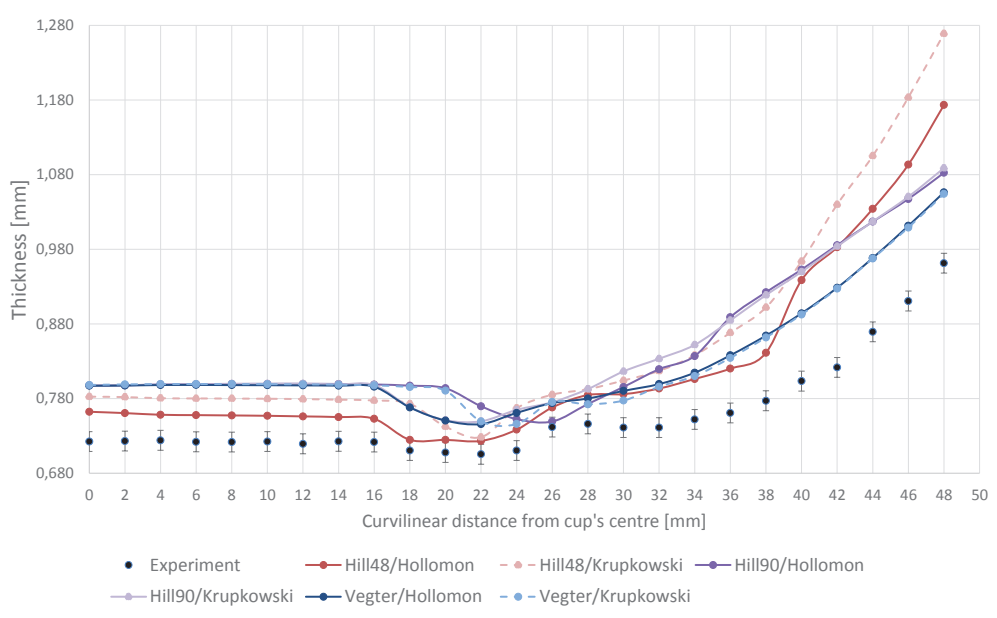

Fig. 5: Thickness distribution of a drawn cup measured in (a) $0^{\circ}$ (b) $45^{\circ}$ and (c) $90^{\circ}$ with respect to the rolling direction.

every combination shown about $1-2.5$ kN higher values of punch force than experiment. Higher differences can be seen after reaching maximum of punch force. During decreasing of force closest to real experiment was combination of Vegter yield function and Hollomon hardening law. Although changing friction coefficient can dramatically change results of punch force [20].

Also the thickness distribution of cup was measured and compared with numerical simulation. Changes in wall thickness of experimental samples was measured by micrometre in three different directions and measured points were $2 \mathrm{~mm}$ from each other. On the bottom of the wall thickness is equal to the original material, the more the approaching the cup radii, thickness started to decrease. After cup radii was complete created thickness began to grow up to $139.9 \%$ of the original thickness. As was expected Hill 48 yield function shows biggest difference from experimental sample. Hill 90 and Vegter yield functions with combination of Krupkowski hardening law shows much better agreement with drawn cup. Figure 5 (a), (b), (c) show thickness distribution in cup compared with numerical simulation.

We can see that the results of numerical simulation are in a good agreement with the thickness of real sample. On the cup walls we can see rapid increase of thickness as a result of material compression in the circumference at flange, which is clearly visible in Figure 6. The cup was fully drawn without any cracks occurred. The most critical was area right behind the bend, due to minimum thickness of a cup. Strain on wall thickness is large, due to ironing effect. The only risk on the walls was secondary wrinkling, but using appropriate blankholder force this effect was excised. Figure 6 shows some results of numerical simulation using Vegter yield function and Krupkowski hardening law.
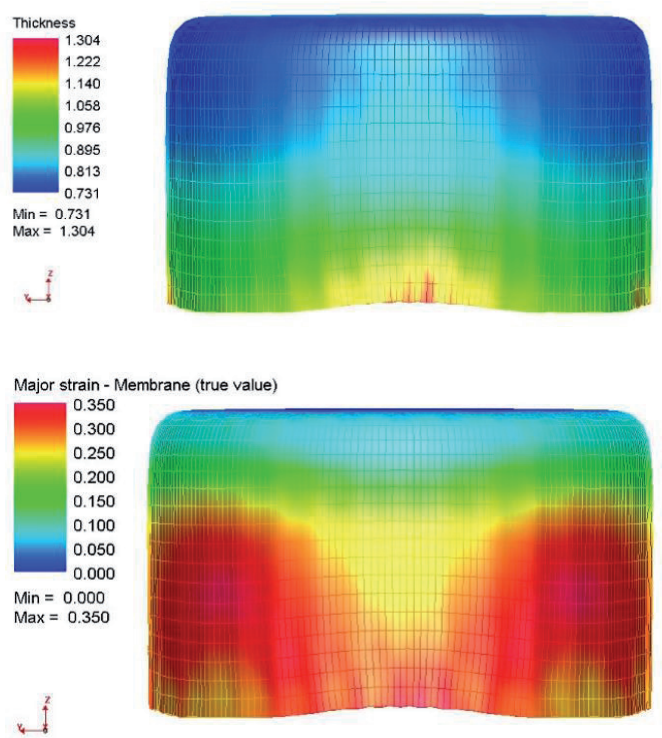

Fig. 6: Results of numerical simulation in drawn cup using Vegter yield function and Krupkowski hardening curve (a) Thickness distribution (b) Major strain distribution. 


\section{Conclusions}

The aim of this work was to create material model which will most realistically describe behavior of material AW 5754 H11 during deep drawing. In order to achieve that, the combinations of yield function (Hill 48, Hill 90 and Vegter Lite) and hardening laws (Hollomon and Krupkowski) was compared on explicit simulation software. In addition to numerical simulation experiment on real samples has been carried out, with the same technological conditions in order to a compare results from numerical simulation and real experiment. On the basis of the research, which have been in this area carried out so far, it has been shown that the condition plasticity under Hill 48 are not suitable for Al alloys as other advanced models. To create material model was therefore also used condition plasticity under Hill 90 and Vegter.

To determinate the accuracy of material model the comparison of ear profile, punch force and thickness distribution was carried out. From the ear profile point of view best results were measured using the Vegter yield function. From the hardening law point of view was the more accurate values reach by Hollomon hardening law. From the punch force point of view were the most accurate values identified when Vegter yield function was used in combination with Hollomon hardening law. When we compare results of thickness distribution in material, the most accurate values were measured on material model, which used combination Vegter yield function and Krupkowski hardening law.

On the basis of the achieved results we can say that yield function have bigger impact on material model than hardening law. From compared yield functions most similar results were achieve by using Hill 90 and Vegter yield function. By comparing Hollomon and Krupkowski hardening law, Hollomon hardening law was Hollomon hardening law more accurate for ear profile and punch force. In thickness distribution was more accurate Krupkowski hardening law. Results from numerical simulation are in good agreement with experimental results. To reach better conformity of numerical results with experiments means keeping one combination of yield function and hardening cure and change technological conditions as friction coefficient, blankholder force and punch speed to achieve even better agreement with real experiment.

\section{Acknowledgments \\ The authors gratefully acknowledge the financial support of the project VEGA 1/0872/14.}

\section{References}

[1] Zhou, J., Wang, B., Lin, J., Fu, L. (2013). Optimization of an aluminum alloy anti-collision side beam hot stamping process using a multi-objective genetic algorithm. Archives of Civil and Mechanical Engineering, 13, 401-411.

[2] Abe, Y., Ohmi, T., Mori, K., Masuda, T. (2014). Improvement of formability in deep drawing of ultra-high strength stee sheet by coating of die. Journal of Mechanical Processing Technology, 214, 1838-1843.

[3] Miller, W.S., [et al.] (2000). Recent development in aluminium alloys for the automotive industry. Material Science and Engineering, A280, 37-49.

[4] Aluminum in cars: Unlocking the light-weighting potential, from http://www.european-aluminium.eu/wp-content/ uploads/2013/10/.

[5] Arwidson, C. (2005). Numerical Simulation of Sheet Metal Forming for High Strenght Steels. Luleâ University of Technology. Sweeden.

[6] Slota, J., Gajdoš, I., Olexová, M. (2009). Numerická simulácia procesu hlbokého tahania a jej verifikácia. MMaMS, 175178.

[7] Zhou, J., Wang, B., Jin, J., Fu, L., Ma, W. (2014). Forming defects in aluminum alloy hot stamping of side-door impact beam. Transactions of Nonferrous Metals Society of China, 24, 3611-3620.

[8] Banabic, D., Dannenmann, E. (2001). Prediction of the influence of yield locus on the limit strains in sheet metals. Materials Processing Technology, 273-281.

[9] Banabic, D., Bunge, H.J., Pöhlandt, K., Tekkaya, A.E. (2000) Formability of Metallic Materials. Springer, Verlag Berlin Heidelberg.

[10] Banabic, D., [et al.] (2004). FLD teoretical model using a new anisotropic yield criterion. Materials Processing Technology, 273-281.

[11] Yuguo, A., Vegter, H. [et al.] (2011). A novel yield locus description by combining the Taylor and the relaxed Taylor theory for sheet steels. Internationl Journal of Plasticity, 356368

[12] Barlat, F., [et al.] (1991). A six-component yield function for anisotropie material. Plasticity 7, 125-137.

[13] Hill, R. (1948) A theory of the yielding and plastic flow of anisotropic metals. Proc. Roy. Soc., London.

[14] Marciniak Z., Duncan J. L., Hu S.J., (2002). Mechanics of sheet metal forming. Proc. Roy. Soc., London, 
[15] PAM-STAMP 2G 2009 - User`s guide. ( 2009 ESI Group

[16] Banabic D. (2010). Sheet metal forming processes. Springer, Verlag Berlin Heidelberg.

[17] Tomáš M. (2011). Numerická simulácia procesu hlbokého tahania. Transfér inovácií, 10/2011, 129-132.

[18] Bruschi S., [et al.] (2014). Testing and modelling of material behaviour and formability in sheet metal forming. CIRP Annals - Manufacturing Technology, 63, 727-749.

[19] Vegter H., Boogard A. H. (). A plane stress yield function for anisotropic sheet material by interpolation of biaxial stress states.

[20] Vegter H., An Y., [et al.] (2003). Characterisation and modelling of the plastic material behavior and its application in sheet metal forming simulation. COMPLAS VII, 1-20.

[21] Nový J., Vaché V., Sobotka J. (2013). Influence of used yield function in deep drawing simulation of highly anisotropic aluminum alloy. IDDRG 2013 Conference, 273-277.

\section{Biographical notes}

Ing. Marek Šiser, is an internal Phd. student at Department of Computer Aided Technologies at Faculty of Mechanical Engineering, Technical University of Košice. His dissertation topic is: Limited states of deformation of light alloy sheets. He is focusing mainly on numerical simulation of stamping processes of Al alloys.

Ján Slota, doc. Ing. PhD., (1974). Currently works as associate professor at Department of Computer Support of Technology. He is graduated on Faculty of Mechanical Engineering, Technical University of Košice, where he received also scientific degree PhD. and where he habilitated at the field of mechanical engineering processes and materials. His research field is oriented on application of numerical simulation of sheet metal forming processes. He is author of 2 monographs, 5 university textbook and more than 100 publications in journals and conference proceedings at Slovakia and abroad. He is a member of The International Deep Drawing Research Group (IDDRG). He has been worked on several grant projects, research tasks and many projects solved for industry. 